\title{
Prevalence of the root canal treatment errors and its related factors in patients treated by undergraduate dental students
}

\author{
Dadresanfar B ${ }^{1}$, Mohammadzadeh Akhlaghi N² and Z. Khodabakhsh ${ }^{3 *}$ \\ ${ }^{1,2}$ Assistant Professor of Endodontic Department, Islamic Azad University, Dental Branch, Tehran, Iran \\ ${ }^{3}$ Postgraduate Student of Operative Department, Islamic Azad University, Dental Branch, Tehran, Iran
}

\begin{abstract}
Since errors of root canal treatment can result in tooth loss, it is important to study effective factors on incident of these errors. In recent years, aiming at reducing errors of root canal treatments and improving performance of dental department in Islamic Azad University, Tehran, facilities were provided which included apex locator, teaching Passive-step back in pre-clinic period and presence of professional assistants and professors who helped students. Studying and investigating errors during treatment by students and providing proper preventative solutions increases the chance of successful treatment of patients. According to the changes in methods of teaching root canal preparation and considering benefit that annual and biennale assessment of prevalence of errors during the treatment has for studying educational performance and future planning, in this study we studied prevalence of errors during root treatment by dental students in general dentistry major and its effective factors, in order to study whether these applied changes reduced errors or not? Firstly, it is hypothesized that effective factors on this errors include quality of radiography, numbers of radiographies, patients' age, type of tooth, type of jaw, canal curvature, periapical lesion, student's semester of the study, student's gender, and numbers of treatment sessions, first treatment of root and second treatment of root. In this research 840 record of patients who had received root canal treatment in public Endodontics sector were evaluated from 2010/9/23 to 2012/09/23. Firstly, two endodontists were calibrated in order to make sure that kappa coefficient is positive and they both agreed on that, and then endodontists, separately, completed data forms pertinent to errors during root treatment and related factors. Prevalence of errors was identified in the samples and then role of associated factors was evaluated by logistic regression as statistical test. And after first evaluation of records, sample of study consists of 613 teeth (1131 canals) which out of them 567 teeth received RTC and 46 teeth received re treatment (Redo). Results indicated that there is statistical difference in frequency of errors
\end{abstract}

\section{ARTICLE INFORMATION:}

*Corresponding Author: Khodabakhsh_narges@yahoo.com Received $27^{\text {th }}$ June, 2017

Accepted after revision $27^{\text {th }}$ Sep, 2017

BBRC Print ISSN: 0974-6455

Online ISSN: 2321-4007 CODEN: USA BBRCBA

: Thomson Reuters ISI ESC and Crossref Indexed Journal

NAAS Journal Score 2017: 4.31 Cosmos IF: 4.006

๑ A Society of Science and Nature Publication, 2017. All rights reserved.

Online Contents Available at: http//www.bbrc.in/

DOI: $10.21786 / \mathrm{bbrc} / 10.4 / 12$ 
during first root treatment and re treatment. In addition, factors including jaw type, tooth type, canal curvature, periapical lesion, and student's semester of study have significant effect on Non homogene-Exact filling length 'Transportation 'Ledge' Over filling's error. However, numbers of treatment sessions was effective with low correlation. Comparing frequencies of errors during root treatment in this study and paper, it was clarified that adding tools such as apex locator, teaching Passive-step back in pre-clinic period and presence of professional assistants and professors who helped students reduces errors during root treatment.

\section{KEY WORDS: DENTAL STUDENTS, RADIOGRAPHIC ENDODONTIC ERRORS, QUALITY OF ROOT CANAL TREATMENT}

\section{INTRODUCTION}

Root treatment, aiming at preventing periapical periodontitis and improving periapical lesion, has been recognized as a complicated treatment in dentistry treatments. This treatment is conducted by removing necrosis pulp, infectious pulp and batteries and via irrigation and preparing canal, mechanical cleaning and also high quality obturation. Epidemiologic studies introduced errors in mentioned procedure as the main reason of treatment failures and imposing higher costs (Lynch 2006; Mozayeni 2006; Yousuf, 2015). It has been indicated that acceptable RCT refers to treatments in which root fillings terminate within $2 \mathrm{~mm}$ of the radiographic apex and that are of adequate homogene density and without void from crown to apical area (Bramanten 1987; Kulic 2011). Applied method for studying quality of root treatment is assessing PA Radiographs that are provided before and after root treatments, radiographically (Kelbauskas 2009; Mosby Co. 2009). Literature review indicated that errors rate varies from 10 to $58 \%$ in different centers while prevalence of these errors rate in academic centers (25-45\%) is significantly higher than professional centers (10-16\%) (Cohen 1998; Er 2006; Estrela, 2017).

Estrela1 et al (2017) performed a research titled as "Common Operative Procedural Errors and Clinical Factors Associated with Root Canal Treatment”. They concluded that in each phase of RCT, an operative error can have adverse implication on prognosis, and these errors show that risk factors lead to failure.Akbar (2015) performed radiographic study of the endodontic treatment's problems and failures. His results illustrated that compare to anterior and premolar teeth, endodontic problems and failures were most common in molars. The most frequently canals with endodontic problems and failures included Mesiobuccal, mesiolingual and distobuccal root canals. Finally, based on results he concluded that the most common cause of endodontic treatment failure was under filling followed by poor filling and over filling and first molar was the most frequently involved tooth with endodontic problems and failures. Yousuf, et al., (2015) studied endodontic procedural errors and showed that the most frequently treated tooth was right permanent mandibular first molar. The least commonly treated teeth were the permanent mandibu- lar third molars. Bakhshi and Shahabi (2015) identified the least mistakes compared to obturation phase, with the most frequent errors including void, overfilling and imperfect cleaning.

A research was carried out by Kulic et al in 2011 in Serbia which indicated that 51.6\% treatments were acceptable with accurate working length and homogeny density. In Fonseka et al (2015) study, it was reported that $74.3 \%$ treatments were acceptable. In addition, in a research in 2008 in Islamic Azad University, endodontics department, Tehran, it was reported that 51.5\% errors happened during root canal treatment while 49.5\% were error-free. Most of the studies illustrated that highest error incident was occurred in posterior teeth (Bramanten CM. 1987; Eleftheriadis GI. 2005; Khabbaz M.G. 2010) and factors including increasing instruction hours reduces errors (Yousuf, W. 2015). Study and consideration of students' errors during treatment and providing appropriate preventive ways increase treatment success in patients (Bramanten CM. 1987) Recent years, facilities including apex-locator, teaching Passive-step back method in pre-clinic, presence of professional assistants and professors who helped students were added into endodontics department of Islamci Azad University in order to reduce errors during treatment.

Based on literature review (Estrela, 2017; Lynch 2006; Yousuf, 2015), popular errors during endodontic treatments are as follow:

Last years equipment including teaching Passivestep back method in pre clinic and presence of professional assistants helping students were applied in order to reduce errors during treatment in endodontic sector. According to the changes made in methods of teaching root canal preparation and considering the benefits that annual and biennale assessment of prevalence of errors during the treatment has for studying educational performance and future planning, thus due to lack of information about the subject in endodotics sector of Islamic Azad University, Tehran, and also because of differences and lacks of previous researches (Er 0. 2006 and Yousuf 2015), studying students' error during treatment and providing proper methods increase chance of successful treatment of patients. This study, therefor, investigates prevalence of errors during root trees and related factors in patient referring to endodontics sector of Islamic Azad 
Table 1. popular errors during endodontic treatments are as follow

\begin{tabular}{|c|c|c|}
\hline & Error type & Description \\
\hline 1 & Under filling & Space between canal obturation and radiographic apex is more than $2 \mathrm{~mm}$ \\
\hline 2 & Over filling & Radiographic beyond apex filling \\
\hline 3 & Non-homogen & Lack of homogene density of filling material from coronal area to apical area \\
\hline 4 & Ledge & Deviation from main path of canal and creating one step in some cases is cause of underfilling \\
\hline 5 & Transportation & Deviation from main path of canal and finding new path in root \\
\hline 6 & Zipping & Perforation of apical area which results in reverse cone and it disrupts apical seal \\
\hline 7 & Strip perforation & Association of pulp space with periodontal space in root branching region \\
\hline 8 & Cervical perforation & Association of pulp space with periodontal space in cervical region of tooth \\
\hline 9 & Forcation perforation & Association of pulp space with periodontal space in forcal region of tooth \\
\hline 10 & Broken Instrument & Broken instrument that is not extracted from canal \\
\hline 11 & Gouging & $\begin{array}{l}\text { Over } \\
\text { Opening cavity more than required space due to not locating grinder in longitudinal axis of } \\
\text { tooth or futile attempt for accessing to the pulp }\end{array}$ \\
\hline
\end{tabular}

University, Tehran, during 2010-2012 in order to find out whether these applied changes reduced error or not?

\section{MATERIALS AND METHODS}

All people who received root treatment from 2010/9/23 to 2012/09/23 in public Endodontics sector in Islamic Azad University; Tehran belonged to the population of the current study. Then, out of endodontics sector records' list that belonged to two years and was gathered statistically, accurate records were selected and studied. In this study, research method was performed by existing data which collected by observation and filing information forms. In addition, samples were selected statistically from all treated patients by dentistry students in general coarse. Out of 840 selected records, 227 records (27\%) were eliminated due to poor radiography quality (182 records, 21.6\%) and lack of sufficient radiography (45 records, 5.3\%)

Records that lacked final radiography, or did not contain at least both diagnostic and final radiography and also records that, in spite of second recording, their radiographic quality was poor were eliminated from the study. Lack of radiography quality happens due to manual radiography developing and fixing by student in public sector of endo which results in over developing the films, insufficient fixing, and lack of PA Radiographs quality. Assessing quality of student's performance in root treatment procedure was conducted in two steps including preparation and root canal obturation based on recorded radiographic images in patients' records. Nevertheless, there are 2 dimension images instead of 3 dimension structures, this system has been applied in different studies (Cohen 1998; Guttman 1997).
Assessing images of all records was conducted by two experts from university endodontic sector, separately, by microscope with at times enlargements and desktop negatoscope. Before study, observers agreed on similar interpretation for radiographic PA Radiograph after performing an experiment. Evaluators were calibrated and Kappa coefficient was reported as 0.88 which proved there is perfect coefficient of agreement among evaluators. Due to perfect coefficient of agreement among evaluators, mentioned samples were assessed again in cases with no agreement among observers. This method was utilized by Khabbaz et al. (2010).

For PA Radiograph homogenization by observers, ray radiation direction considered mesial in all radiographies. Poor radiographies were fixed again and reevaluated. Records which lacked 2 diagnostic and final radiographies were eliminated. Two endodontists conducted diagnostic and final radiographies and used microscope at five times enlargement and one negatoscope. In addition, some rare errors mentioned in the record and they were not observable in radiography but they were mentioned in the record were studied. Firstly, errors' evaluators explained errors, then coefficient of concordance (Kappa) were identified and then records' assessment was started. Evaluators were calibrated in order to make sure that Kappa coefficient is positive and they are compatible. For preventing errors of answers, each endodontist filled data forms separately and then errors that endodontist were agreed upon considered as real error. In cases that observers did not agree on, due to perfect coefficient of agreement between evaluators, mentioned samples were reassessed and evaluators agreed on that.

In epidemiologic studies, there are different standards for categorizing root treatment quality. The most prevalent parameters of acceptable treatment categorization 
are length of root canal filling, filling homogenization without void, and absence of iatrogenic errors (Cohen 2006; Haji-Hassani, 2015; Mozayeni 2006). In this study, standards of determining radiographic categorization of root treatment were based on length and density of filling in the absence of iatrogenic errors and they were categorized into two acceptable and unacceptable treatments.

The filling material ends $0-2 \mathrm{~mm}$ shorter than radiographic apex with no visible voids within the material or between the material and root canal walls. 2) Unacceptable treatments: A) the filling material ends more than $2 \mathrm{~mm}$ from radiographic apex or beyond the radiographic apex. B) Visible voids within or between filling material and root canal walls

1. Acceptable treatment: under filling is $0-2 \mathrm{~mm}$ and density of filling material is homogene with no visible void within the material or between crown and apical area. Besides no observable iatrogenic error is in patient's record and in canals.

2. Unacceptable treatment

a. The filling material ends more than $2 \mathrm{~mm}$ from radiographic apex or beyond the radiographic apex

b. Density of filling material in not homogene and there is void between crown to apical area.

c. Iatrogenic error is observed in canals and it is also reported in pateint's record.

In addition, in this study we assessed demographic information of students (gender, and the semester) and factors pertinent to patient and tooth including patient gender, age, tooth location, tooth root numbers, canal numbers, periapical radiolucencies, canal curvature and treatment sessions numbers.

\section{RESULTS AND DISCUSSION}

Results indicated that 61\% first treatments (RCT) were acceptable and 39\% had errors during root treatment. Acceptable treatment which consists of exact length of filling and proper density of filling and no incidence of iatrogenic errors, in anterior teeth was $75.6 \%$, in premolar was $72 \%$ and in molars was $38.4 \%$. Redo were acceptable for $100 \%$ cases and the most prevalent redo tooth was Mandibular second premolar. Previous short filling was identified as the most common cause of redo.

In table 2, there is information about frequency of errors during root treatment in patients who received treatment by dental students in general coarse in endodontics sector of Islamic Azad University, dentistry department, during 2010-2012. In addition, table 2 indicates frequency of errors during root treatment associated to relevant factors.

Based on table 2 and table 3 and results of logistic regression, it is concluded that:

1. 55\% studied canals had curvature which it was more in molar teeth. $24.2 \%$ canals with curvature had errors during root treatment. 14.5\% tooth that received RCT had periapical lesion which was more in mandibular first molar. 47\% canals had periapical error during treatment.

\begin{tabular}{|c|c|c|c|c|c|c|c|c|c|}
\hline \multicolumn{2}{|l|}{ total } & \multicolumn{2}{|l|}{ Molar } & \multicolumn{2}{|l|}{ premolar } & \multicolumn{2}{|l|}{ anterior } & \multicolumn{2}{|l|}{ Error type } \\
\hline Percentage & Frequency & Percentage & Frequency & Percentage & Frequency & Percentage & Frequency & $\infty$ & Tooth type \\
\hline 100 & 7 & 42.8 & 3 & 28.6 & 2 & 28.6 & 2 & \multicolumn{2}{|c|}{ Broken instrument } \\
\hline 100 & 40 & 67.5 & 27 & 20 & 8 & 12.5 & 5 & Homogen & \multirow{2}{*}{$\begin{array}{l}\text { Over filling } \\
\text { Root canal }\end{array}$} \\
\hline 100 & 22 & 59 & 13 & 32 & 7 & 9 & 2 & Nonhomogen & \\
\hline 100 & 35 & 45.7 & 16 & 25.7 & 9 & 28.6 & 10 & Homogen & \multirow{2}{*}{$\begin{array}{l}\text { Under } \\
\text { Filling } \\
\text { Root canal }\end{array}$} \\
\hline 100 & 28 & 67.8 & 19 & 21.4 & 6 & 10.8 & 3 & Nonhomogen & \\
\hline 100 & 102 & 60.8 & 62 & 23.5 & 24 & 15.7 & 16 & \multicolumn{2}{|c|}{$\begin{array}{l}\text { Nonhomogen- Exact filling } \\
\text { length Root canal }\end{array}$} \\
\hline 0 & 0 & 0 & 0 & 0 & 0 & 0 & 0 & \multicolumn{2}{|c|}{ Forcal Perforation } \\
\hline 0 & 0 & 0 & 0 & 0 & 0 & 0 & 0 & \multicolumn{2}{|c|}{ Cervical Perforation } \\
\hline 100 & 5 & 100 & 5 & 0 & 0 & 0 & 0 & \multicolumn{2}{|c|}{ Strip Perforation } \\
\hline 100 & 9 & 100 & 9 & 0 & 0 & 0 & 0 & \multicolumn{2}{|c|}{ Strip preparation } \\
\hline 100 & 25 & 52 & 13 & 16 & 4 & 24 & 6 & \multicolumn{2}{|l|}{ Ledge } \\
\hline 100 & 54 & 72.2 & 39 & 18.5 & 10 & 9.3 & 5 & \multicolumn{2}{|l|}{ Transportation } \\
\hline 100 & 4 & 75 & 3 & 25 & 1 & 0 & 0 & \multicolumn{2}{|l|}{ Zipping } \\
\hline 100 & 6 & 0 & 0 & 33.3 & 2 & 66.7 & 4 & \multicolumn{2}{|l|}{ Gouging } \\
\hline 100 & 567 & 35.8 & 203 & 35.9 & 204 & 28.2 & 160 & & \\
\hline
\end{tabular}




\begin{tabular}{|c|c|c|c|c|c|c|c|c|c|c|c|c|c|}
\hline \multicolumn{2}{|c|}{ Related factors Error } & \multicolumn{2}{|c|}{ gender } & \multicolumn{4}{|c|}{ manual endo coarse } & \multicolumn{6}{|c|}{ Numbers of treatment sessions } \\
\hline & \multicolumn{2}{|c|}{ male } & Female & two & three & \multicolumn{2}{|c|}{ four } & one & two & \multicolumn{2}{|c|}{ three } & Four & Five \\
\hline \multicolumn{2}{|l|}{ No error } & $\begin{array}{l}148 \\
61.7\end{array}$ & $\begin{array}{l}197 \\
60.3\end{array}$ & $\begin{array}{l}192 \\
71.9\end{array}$ & $\begin{array}{l}96 \\
60\end{array}$ & \multicolumn{2}{|c|}{$\begin{array}{l}59 \\
41.1\end{array}$} & $\begin{array}{l}112 \\
70.4\end{array}$ & $\begin{array}{l}185 \\
63.8\end{array}$ & \multicolumn{2}{|c|}{$\begin{array}{l}45 \\
44.1\end{array}$} & $\begin{array}{l}4 \\
28.6\end{array}$ & $\begin{array}{l}1 \\
50\end{array}$ \\
\hline \multicolumn{2}{|l|}{ With error } & $\begin{array}{l}92 \\
38.3\end{array}$ & $\begin{array}{l}130 \\
39.7\end{array}$ & $\begin{array}{l}75 \\
28.1\end{array}$ & $\begin{array}{l}64 \\
40\end{array}$ & \multicolumn{2}{|c|}{$\begin{array}{l}81 \\
57.9\end{array}$} & $\begin{array}{l}47 \\
31.6\end{array}$ & $\begin{array}{l}105 \\
36.2\end{array}$ & \multicolumn{2}{|c|}{$\begin{array}{l}57 \\
55.9\end{array}$} & $\begin{array}{l}10 \\
71.4\end{array}$ & $\begin{array}{l}1 \\
50\end{array}$ \\
\hline \multicolumn{2}{|l|}{ Total } & 240 & 327 & 267 & 160 & 140 & & 159 & 290 & 102 & & 14 & 2 \\
\hline (A) & & & & & & & & & & & & & \\
\hline Related factors & Canal & numbe & & & Toot & typ & & & & & Jaw & typ & \\
\hline Error & one & two & three & four & ante & & Pre & molar & mol & lar & lowe & & upper \\
\hline No error & $\begin{array}{l}205 \\
75.3\end{array}$ & $\begin{array}{l}69 \\
67.6\end{array}$ & $\begin{array}{l}64 \\
40\end{array}$ & $\begin{array}{l}9 \\
28.1\end{array}$ & $\begin{array}{l}121 \\
75.6\end{array}$ & & $\begin{array}{l}147 \\
72\end{array}$ & & $\begin{array}{l}78 \\
38.4\end{array}$ & & $\begin{array}{l}125 \\
53.9\end{array}$ & & $\begin{array}{l}221 \\
66\end{array}$ \\
\hline With error & $\begin{array}{l}68 \\
24.7\end{array}$ & $\begin{array}{l}23 \\
32.4\end{array}$ & $\begin{array}{l}96 \\
60\end{array}$ & $\begin{array}{l}23 \\
71.9\end{array}$ & $\begin{array}{l}39 \\
24.4\end{array}$ & & $\begin{array}{l}57 \\
28\end{array}$ & & $\begin{array}{l}125 \\
61.6\end{array}$ & & $\begin{array}{l}107 \\
46.1\end{array}$ & & $\begin{array}{l}114 \\
34\end{array}$ \\
\hline Total & 273 & 92 & 160 & 32 & 160 & & 204 & & 203 & & 232 & & 335 \\
\hline (B) & & & & & & & & & & & & & \\
\hline Related factors & Can & curva & ture & & lesion & & & Patien & nt ag & & & & \\
\hline & Dire & t canal & $\begin{array}{l}\text { Curv } \\
\text { cana }\end{array}$ & $\begin{array}{l}\text { ved } \\
\text { al }\end{array}$ & $\begin{array}{l}\text { With } \\
\text { error }\end{array}$ & $\begin{array}{l}\text { No } \\
\text { errc }\end{array}$ & & $\begin{array}{l}\text { Under } \\
30\end{array}$ & & $\begin{array}{l}\text { Betwe } \\
30-45\end{array}$ & & & $\begin{array}{l}\text { ler } \\
\text { n } 45\end{array}$ \\
\hline No error & $\begin{array}{l}412 \\
84.1\end{array}$ & & $\begin{array}{l}451 \\
75.8\end{array}$ & & $\begin{array}{l}44 \\
53\end{array}$ & $\begin{array}{l}819 \\
81.7\end{array}$ & & $\begin{array}{l}143 \\
60.3\end{array}$ & & $\begin{array}{l}123 \\
57.5\end{array}$ & & $\begin{array}{l}80 \\
69\end{array}$ & \\
\hline With error & $\begin{array}{l}78 \\
15.9\end{array}$ & & $\begin{array}{l}144 \\
34\end{array}$ & & $\begin{array}{l}39 \\
47\end{array}$ & $\begin{array}{l}183 \\
19.3\end{array}$ & & $\begin{array}{l}94 \\
39.7\end{array}$ & & $\begin{array}{l}91 \\
42.5\end{array}$ & & $\begin{array}{l}36 \\
31\end{array}$ & \\
\hline Total & 490 & & 335 & & 83 & 100 & & 237 & & 214 & & 116 & \\
\hline
\end{tabular}

2. $39.7 \%$ treatments conducted by female students and 38.3\% performed by male students had errors during the treatment. But there was no significant difference between students' gender and errors during treatment ( $\mathrm{p}>0.05)$.

3. $71.4 \%$ four sessions treatment and $29.1 \%$ one session treatment had errors during the treatment. It means that there was significant difference between errors rate during treatment and treatment sessions number $(p<0.001)$. However, considering correlation coefficient $(\varphi=0.21)$, this relationship was poor.

4. Considering root treatment error, there was significant difference between two jaws $(p=0.004)$. Regarding that its incidence in mandibular teeth was significantly more than maxillary teeth (34\%). Considering correlation coefficient, $\varphi=-0.12$, this error was more prevalent in mandibular than upper jaw.

5. Error incidence rate by students in manual endo coarse 2 was identified $28.1 \%$, by manual endo coarse 3 was 40\%, and by manual endo coarse 4 was $57.1 \%$, which indicated that there is significant relationship between errors during treat- ment and students study in manual endo coarse $(p<0.001)$ and considering correlation coefficient, $\varphi=0.52$, this relationship was average.

In addition, results obtained from prevalence of errors during treatment indicated that:

a. Non homogen-Exact fillng length was identified in $13.4 \%$ canals (145 canal) as the most prevalent error in root filling procedure (filling with in adequate quality in exact length of function). This error was significantly more prevalent in molar teeth canal $(60.8 \%)$ than premolar and anterior teeth $(p<0.001)$ but considering correlation coefficient, $\varphi=0.25$, this relationship was poor. This error was $35.3 \%$ in mandibular molars and 25.5\% in maxillary molars. Highest prevalence was identified in mandibular molars and mesiobacal canal (18\%) and then it was observed in mesiolingual (17.2\%).

b. In field of errors during root canal preparation, the most common error was transportation which was observed in 9.5\% teeth (54 teeth) highest rate of this error happened among molars which prevalence rate was $72.3 \%$ and highest prevalence happened in mesiobacal canal of mandib- 
ular first molar. There was significant relation between transport and canal curvature $(p<0.05)$. However, considering correlation coefficient, $\varphi=$ 0.1 , this relation was weak. There was significant difference in transport incidence among molar teeth (72.2\%) and premolars (18.5\%) and anteriors (9.3\%) $(\mathrm{p}<0.05)$.

c. Second prevalent error during canal preparation was ledge which was observed $4.4 \%$ of total teeth. There was significant relation between canal ledge and curvature $(\mathrm{p}<0.05)$ however considering correlation coefficient, $\varphi=0.06$, this relation was poor. In molar teeth, error prevalence was 52\% which was more than pre molar and anterior teeth. In addition, ledge prevalence was significantly higher in mandibular (40\%) than maxillary (12\%) $(\mathrm{P}<0.005)$. Highest rate of error happened in first mandibular (32\%) and mesial root and it is observed equally in mesiobacal canals (25.6\%) and mesiolingual (25.6\%).

d. Over filling has been studied in 6.8\% canals and it was identified that $4.2 \%$ were over homogene and $2.6 \%$ were over non-homogene. the highest prevalence rate happened in mesiolingual canals of mandibular molars. Significant difference was observed in overfilling and teeth with priapical lesion $(\mathrm{p}<0.05)$ however considering correlation coefficient, $\varphi=0.08$, this relation was very poor.

e. Foracal Perforation and Cervical Perforation were not observed. 6 Strip Perforation cases, 7 Broken Instrument cases, 4 zipping cases, 6 Gouging cases and 9 Strip Preparation cases were identified and there was not significant relationship with related factors.

In this study, maximum error happened in root filling step, Non homogen-Exact filling length (filling with inadequate quality in exact length of function) and the most prevalent error in field of errors during root canal preparation was transportation error. Second prevalent error during canal preparation was ledge. In this study, 613 teeth including 1131 canal were evaluated which consists of 567 teeth which received RCT and 46 teeth received retreatment. Acceptable treatment in anterior teeth was 75.6\%, 72\% in premolars and 38.2\% in molars. $100 \%$ redo were identified as acceptable treatment and the most prevalent retreated tooth was mandibular second premolar and under-filling was identified as the most prevalent cause of retreat.

In this study, similar to Kulic et al (2011), multi root teeth which had error during treatment, even in one canals, was considered as unacceptable treatment. Unal et al (2011) reported highest prevalence of acceptable treatment in anterior teeth was $90.1 \%$ and the least prevalence was reported in $46.6 \%$ molars. In $71 \%$ anterior teeth, 61\% premolars and 30\% molars were reported as acceptable treatment prevalence by Khabbaz et al (2010). In current study, 61\% treatments were acceptable and 39\% treatment were unacceptable. Acceptable treatment in anterior teeth was 75.6\%, in premolars was 72\% and in molars was 38.2\%.

Mozayeni et al (2006) reported that the most prevalent error during root canal preparation was transportation. In addition, Dadresanfar et al (2008) reported that transport prevalence was $27.5 \%$. Statistical difference of these findings can be due to applying Passive-step back preparation method in pre clinic coarse, applying Gates-Gliden drills for coronal preparation of root which reduces coronal interferences from deviation of first path canal and also due to professional assistance and their help to students. High prevalence of transportation in molar teeth its significant difference with anterior and pre molar teeth can be due to complicated anatomy of these teeth, high numbers of canals and curvature of canals in these teeth. There was significant statistic relationship between root canal curvature and transportation which shows there is potential effect of root canal curvature on canal displacement. Lack of attention to canal curvature, not providing Pre curve to files during preparation of curved canals and lack of removing interferences of root canal Orifices can be reasons of high transportation rate in canals.

Second prevalent error during anal preparation was ledge. Al-Kahtani et al reported that ledge prevalence was 7.5\% which is compatible with current study. Eleftheriadis et al reported that ledge prevalence in molars were $34.9 \%$ which is caused by step-back technic and curvature of molar canals. Less prevalent of ledge in this study can be due to using other canal preparation technics including Passive-step back and applying files with higher flexibility such as Flexo File by dentistry students.The most prevalent error during root filling was Non homogen-Exact fillng length. More errors in molars can be because of lack of adequate access of students to these teeth and in adequate canal flaring which is caused by their stress for bad incidents. Because inadequate canal flaring prevents suitable penetration of spreader, especially stainless spreaders, which will cause bad filling density.

Er et al (2006) reported that 48.8\% filling had inadequate density. In addition, Khabbaz et al (2010) stated that 33.5\% filling had inadequate density and Kulic L et al (2011) in 25\% and Dadresanfar et al reported that $29.2 \%$ filling had inadequate density. Statistical difference of these results with mentioned studies can be stemmed from increase of assistants and professors' 
numbers and continuous study of patients during treatment by professors via providing constancy control radiographies during obscuration which reduces prevalence of errors during canal filling.

Maximum error prevalence of over filling was find out in mesiolingual canal of mandibular molars and there was significant statistical difference between overfilling and teeth with periapical lesion, because periapical lesion root top resorption so students cannot deal with length control easily then it ends to overfilling. Kelbauskas et al (2009) reported that 5.42\% had overfilling which was compatible with this study. Kulic et al (2011) reported3.3\% overfilling which this low prevalence can be due to less numbers of their samples (306 canal). Er et al (2006) reported 13\% overfilling cases and Khabbaz et al reported $22.6 \%$ overfilling. Statistical difference of current studies with those can be due to studying more canals in samples (1109 canals).

Highest rate of underfilling error happened in Mesiobacal canal of mandibular molars. It can be due to higher rate of transportation and ledge in molars which results in diversion from main canal path and interference in filling steps. In addition in Step-back technic there is possibility of debris and dentin debris packaging in apex top so there is no way for filling with exact length. Kelbauskas et al (2009) reported that in 10.5\% cases, underifilling happened. They also reported that the main reason is ledge and debris packaging.

\section{CONCLUSION}

It seems that using tools such as apex locator, presence of professional assistants and attention of professors of the related sector and also applying Passive-Step back in curved canals by some students reduces preparation error rate and errors of root canal filing. However utilizing more flexible files, emphasizing on before-duringand after treatment radiographies, meticulous supervision of professors during treatment and presence of lower semester students with higher semester students and professional assistants in third and second year of experience could be considered as a guide for increasing quality of root treatments and reducing errors.

\section{REFERENCES}

Barriesh-Nusair KM, Al-omari MA, Al-Hiyasat AS. (2004). Radiographic technical quality of root canal treatment performed by dental student at the Dental Teaching Center In Jordan. J Dent 3:301-7

Bramanten CM, Berbert A, Barges RP. (1987). A Methodology for Evaluation of Root Canal Instrumentation. Endod J 13: 243.
Cohen S, Burns RC. (1998). Pathways of the pulp,7 th ed,Missouri, Mosby. ch8:209.

Cohen S, Burns RC. (2006). Pathways of the pulp. 9th ed. St. Louis: Mosby, Elsevier. ch26:1025-1026, ch9:327

Dadresanfar B, Mohammadzadeh Akhlaghi N, Vatanpour M, Atef Yekta H. (2008). Technical quality of root canal treatment performed by undergraduate dental students. Iranian Endodontic J 3:73-78

Eleftheriadis GI, Lambrianidis TP. (2005). Technical quality of root canal treatment and detection of iatrogenic errors in an undergraduate dental clinic. Int Endod J 38:725-34.

Er O, Sagsen B, Maden M, Cinar S, Kahraman Y. (2006). Radiographic technical quality of root canal filling performed by dental students in Turkey. Int Endod J, 39, 867-72

Estrela, C., Pécora, J. D., Estrela, C. R., Guedes, O. A., Silva, B. S., Soares, C. J., \&t Sousa-Neto, M. D. (2017). Common Operative Procedural Errors and Clinical Factors Associated with Root Canal Treatment. Brazilian Dental Journal, 28(2), 179190.

Farzaneh M, Abitbol S, Friedman Sh. (2004). Treatmen Outcome in Endodontic: The Toronto study. Phases 1 and 2: Orthograde Retreatment. Endod J 30:627-33

Friedman Sh, Abitbol S, Lawrence H. (2003). Treatment Outcome in Endodontics: The Toronto Study. Phase 1: Initial Treatment. Endod J 29:787-93

Guttman J, Dumsha T, Lovdahl P, Hovland E. (1997). Problem solving in endodontics 3th ed mosby U.S.A, 5-6

Haji-Hassani, N., Bakhshi, M., \&t Shahabi, S. (2015). Frequency of Iatrogenic Errors through Root Canal Treatment Procedure in 1335 Charts of Dental Patients. Journal of international oral health: JIOH, 7(Suppl 1), 14.

Ingle J, Bakland L (2008). Endodontics. 6th Ed. Ch27:921

Javidi M, Shoja Razavi A, Esmaieli H. (2006). A Comparision between conventional and digital radiography in estimating the working length of root canal. J Dent, 30:30-44

Kelbauskas E, Andriukaitien L, Irena N. (2009). Quality of root canal filling performed by undergraduate students of odontology at Kaunas University of Medicine in Lithuania. Stomatologic, Baltic. Dental and Maxillofacial J 1:92-96

Khabbaz M.G, protogerou E., douka E. (2010). Radiographic quality of root fillings performed by undergraduate students. Int Endod J 43:499-508

Kulic L, Nogo-Zivanovic D, Krunic J, Vujaskovic M, Stojanovic N. (2011). Radiological Assessment of the Quality of Root Canal Filling in Teeth Endodontically Treated at Students' Practical session. Serbian Dent J; 3:139-143

Lynch CD, Burke FM. (2006). Quality of root canal filling performed by under graduate dental students on single rooted teeth.Eur J Den;10:67-22

Mozayeni MA, Asnaashari M, Modaresi J. (2006). Clinical and radiographic evaluation of procedural accidents and errors during root canal therapy. Iranian Endodontic J 97-100 
Pratten DH, McDonald NJ. (1996). Comparison of radiographic and electronic working lenghts. J Endod; 22:173.

CV Mosby Co. (2009) Toronto; Ch18:322

Unal GC, Kececi AD, Kaya BU, Tac AG. (2011). Quality of root canal fillings performed by undergraduate dental student. Eur J Dent 3:324-30
Yousuf, W., Khan, M., \&t Mehdi, H. (2015). Endodontic procedural errors: frequency, type of error, and the most frequently treated tooth. International journal of dentistry, 2015.

Zinman EJ. (2002). Records and legal responsibilities. In: Cohen S, Burns RC, editors. Pathways of the pulp. 8th ed. St.Louise: Mosby; P. 400. 